\title{
Gene Therapy for Human Sensorineural Hearing Loss
}

\author{
Yin Ren ${ }^{1,2}$, Lukas D. Landegger ${ }^{1,2,3}$ and Konstantina M. Stankovic ${ }^{1,2,4,5 *}$ \\ ${ }^{1}$ Department of Otolaryngology, Harvard Medical School, Boston, MA, United States, ${ }^{2}$ Eaton Peabody Laboratories, \\ Department of Otolaryngology, Massachusetts Eye and Ear, Boston, MA, United States, ${ }^{3}$ Department of Otolaryngology, \\ Vienna General Hospital, Medical University of Vienna, Vienna, Austria, ${ }^{4}$ Program in Speech and Hearing Bioscience \\ and Technology, Harvard Medical School, Boston, MA, United States, ${ }^{5}$ Harvard Program in Therapeutic Science, Harvard \\ University, Boston, MA, United States
}

\section{OPEN ACCESS}

Edited by:

Stefan K. Plontke,

Martin-Luther-Universität

Halle-Wittenberg, Germany

Reviewed by:

Melissa Caras,

University of Maryland, College Park,

United States

Hermona Soreq,

The Hebrew University of Jerusalem,

Israel

*Correspondence:

Konstantina M. Stankovic konstantina_stankovic@

meei.harvard.edu

Specialty section:

This article was submitted to

Non-Neuronal Cells,

a section of the journal

Frontiers in Cellular Neuroscience

Received: 30 April 2019

Accepted: 01 July 2019

Published: 16 July 2019

Citation:

Ren Y, Landegger $L D$ and Stankovic KM (2019) Gene Therapy for Human Sensorineural Hearing Loss. Front. Cell. Neurosci. 13:323. doi: 10.3389/fncel.2019.00323
Hearing loss is the most common sensory impairment in humans and currently disables 466 million people across the world. Congenital deafness affects at least 1 in 500 newborns, and over 50\% are hereditary in nature. To date, existing pharmacologic therapies for genetic and acquired etiologies of deafness are severely limited. With the advent of modern sequencing technologies, there is a vast compendium of growing genetic alterations that underlie human hearing loss, which can be targeted by therapeutics such as gene therapy. Recently, there has been tremendous progress in the development of gene therapy vectors to treat sensorineural hearing loss (SNHL) in animal models in vivo. Nevertheless, significant hurdles remain before such technologies can be translated toward clinical use. These include addressing the blood-labyrinth barrier, engineering more specific and effective delivery vehicles, improving surgical access, and validating novel targets. In this review, we both highlight recent progress and outline challenges associated with in vivo gene therapy for human SNHL.

Keywords: gene therapy, adeno-associated virus (AAV), nanoparticles, blood labyrinth barrier, Anc80L65, tumor penetrating peptide, round window niche

\section{INTRODUCTION}

Hearing loss is the most common sensory impairment in humans and currently disables 466 million people across the world; this number is expected to rise to nearly 1 billion by 2050 (WHO Deafness and Hearing Loss, 2018). It is especially prevalent in the aging population as nearly two-thirds of the U.S. population over the age of 70 years are affected by disabling hearing loss (Lin et al., 2011). Furthermore, congenital deafness affects at least 1 in 500 newborns, with over $50 \%$ of these being hereditary in nature. Most of this burden is due to sensorineural hearing loss (SNHL) which originates from defects in the cochlea, the spiraling organ of the inner ear.

The human inner ear is a small, three-dimensionally complex, fluid-filled structure encased in the densest bone in the body and located deep in the base of skull. Acoustic energy from sound is transmitted to the fluids of the cochlea via vibrations of the tympanic membrane and ossicular chain in the middle ear, producing a traveling wave along the basilar membrane. The length of the cochlea and stiffness of the basilar membrane enables the differentiation of sound frequencies (Manoussaki et al., 2006). This in turn leads to activation of mechanotransduction by hair cells, specialized sensory cells located in the organ of Corti, which turn mechanical stimulation into electrical depolarization. The electrical signal initiated by the inner hair cells (IHCs) is then processed by 
spiral ganglion neurons (SGNs) that make up the auditory nerve and ultimately decoded in the auditory cortex of the temporal lobe (Rubel and Fritzsch, 2002).

The genetic basis for human hearing loss has been under intensive investigation for the past two decades. Initially noted by Gorlin et al. (1995) that a significant portion of hearing loss has an underlying genetic etiology, the number of distinct genes associated with inherited hearing loss has since rapidly expanded with the advent of advanced sequencing technologies. A list of human loci linked with hearing loss has been compiled and regularly updated ${ }^{1}$. Broadly speaking, genetic hearing loss is subcategorized into Mendelian inheritance including both syndromic and non-syndromic cases, or complex inheritance which includes both genetic and environmental factors. Today, there are 115 genes responsible for non-syndromic hearing loss, with 45 autosomal dominant genes, 73 autosomal recessive genes, $5 \mathrm{X}$-linked genes, and additional loci for modifiers, Y-linked, and auditory neuropathy, respectively. On a global scale, the prevalence of hearing loss is highest in Eastern Europe, Central and South Asia, and Asia Pacific approaching 10\%. Regions with lower income and literacy levels also tend to have higher rates of hearing loss (Sheffield and Smith, 2018). Further characterizations of the molecular pathways defined by these genes and loci have been reviewed elsewhere (Dror and Avraham, 2010; Stamatiou and Stankovic, 2013).

Despite our growing knowledge of the molecular underpinnings of auditory development, as well as an expanding armamentarium of deafness genes identified to date, there are no pharmacotherapies clinically approved for SNHL. Current treatments focus on amplification of sound through hearing aids, or via electrical stimulation of auditory neurons through cochlear implantation (CI) for severe to profound deafness. Nevertheless, neither approach restores the native inner ear sensory epithelium. Given the genetic basis underlying many forms of hearing loss and progress in our understanding of the mechanisms of hair cell regeneration and neuronal synapse repair, targeted modulation of affected genes in specific cell types of the inner ear could be a powerful therapeutic strategy. There have been numerous recent reports highlighting the complexity of genetic hearing loss and both non-viral and viral delivery approaches for therapeutic delivery (Chang, 2015; Ahmed et al., 2017; Devare et al., 2018; Lustig and Akil, 2018). In this review, we focus on (1) transport barriers to inner ear drug delivery, (2) viral and nanotechnology carriers that target the inner ear with high precision and efficiency, (3) adult animal models for clinically translatable hearing restoration, and (4) practical surgical challenges in navigating the middle and inner ear.

\section{TRANSPORT BARRIERS TO THE INNER EAR}

The translation of modern molecular therapy into clinical use is hindered by the so-called "delivery" challenge. To engineer a precise and effective inner ear delivery system, one must

${ }^{1}$ http://hereditaryhearingloss.org/ first develop a comprehensive understanding of the anatomic and physiologic barriers that isolate labyrinthine organs from the middle ear space and the brain. The perilymphatic space communicates via the round and oval windows to the middle ear, and via the cochlear aqueduct and cochlear modiolus to the cerebral spinal fluid (CSF) space (Figure 1). The arterioles and venules are located inside bony channels within the scala vestibuli and scala tympani, respectively, with the major capillary beds located in the stria vascularis, spiral ligament, and spiral ganglion (Axelsson, 1988). A lymphatic system is also thought to provide clearance and drainage of the middle and inner ear (Lim and Hussl, 1975). On a microscopic scale, specialized cell layers consisting of tight junctions and endothelial cells lining cochlear blood vessels form the blood-labyrinth barrier (BLB), an intricate network that tightly regulates the transport of macromolecules and ions between the vascular compartment and the inner ear.

The BLB has been compared to the blood-brain barrier (BBB), a complex system of endothelial cells, basement membrane, pericytes, and astrocytes that isolates and protects the central nervous system (CNS). While the complexity of the BBB renders delivery of macromolecule therapeutics challenging, it also presents unique opportunities for drug delivery across the barrier (Pardridge, 2016). Novel ways to improve therapeutic delivery include modifications of the drug to improve pharmacokinetics and lipophilicity, development of "Trojan horse" carriers or analogs for endogenous ligands, inhibition of drug efflux, and modulation of BBB permeability (Banks, 2016). Recent promising work in nanotechnology has overcome this bottleneck and bypass the BBB in pathologic conditions such as traumatic brain injury (Smith et al., 2016). These promising strategies should be emulated and adapted to enhance drug delivery across the BLB into the inner ear.

Under physiologic conditions, the intact BLB is thought to maintain ionic homeostasis, isolate from pathogens in the blood, and thereby contribute to the semi immune-privileged nature of the inner ear (Salt and Hirose, 2018). By contrast, this barrier can become "leaky" upon exposure to toxic levels of noise or ototoxic medications through activated macrophages (Kopke et al., 1999; Suzuki et al., 2002). Interestingly, evidence suggests that a compromised BLB through systemic exposure to lipopolysaccharide does not correlate with a loss of hearing (Hirose et al., 2014; Hirose and Li, 2019). Therefore, the dynamic nature of the BLB's permeability could be harnessed as a window for intracochlear therapeutic delivery. Indeed, strategies to temporarily enhance the permeability of tissue barriers have seen success in delivering macromolecule drugs to tumors or the brain that would be otherwise difficult to traverse (Ren et al., 2012; Kwon et al., 2016). Future experimental animal models will need to specifically and precisely alter the permeability of the BLB and identify new epitopes that are unveiled in the cochlear sensory epithelium or neurons. Strategies to reduce lymphatic or macrophage-mediated clearance of delivered drugs could effectively improve the biodistribution of the drug within the desired tissue. Future interventions that transiently enhance macromolecule transport across the BLB without causing significant cellular damage may serve as useful adjuncts to improve drug penetration. 

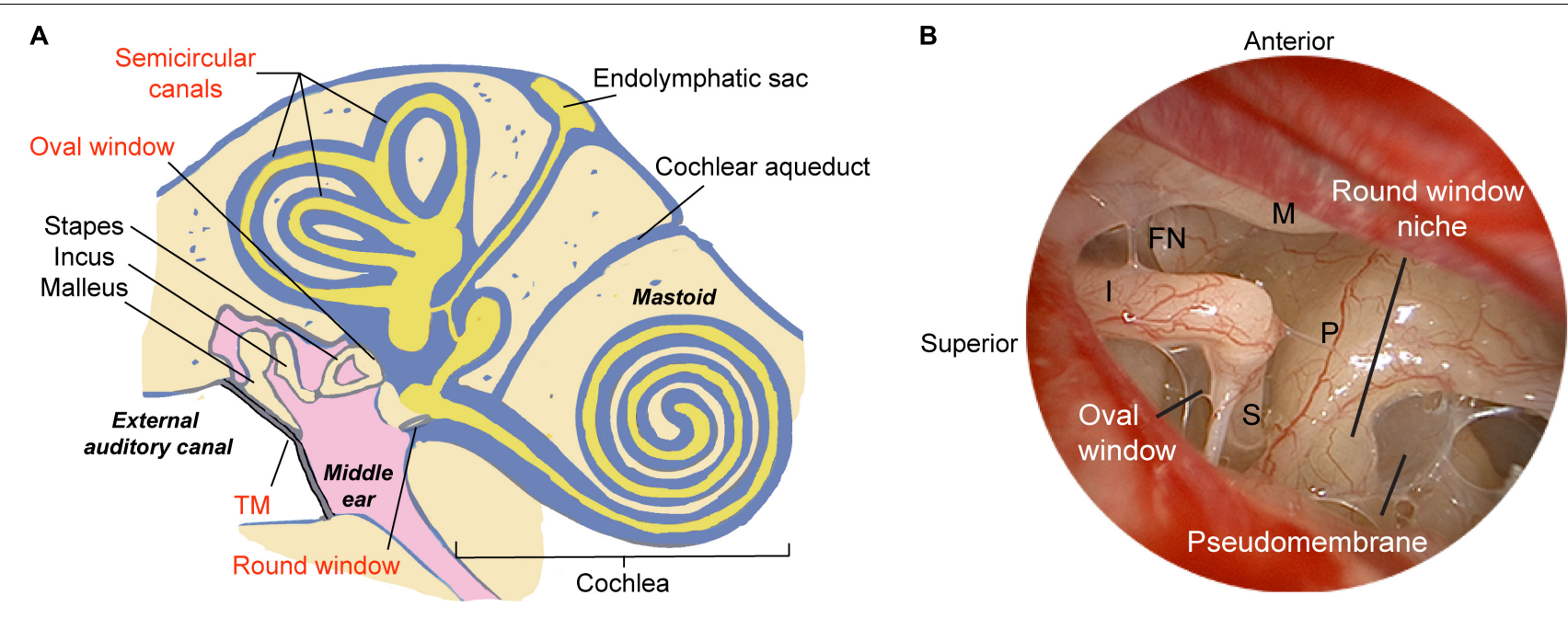

FIGURE 1 | Schematic illustrating methods of delivering therapeutics to the human ear. (A) The relevant structures through which drugs such as gene therapy agents, nanoparticles, or biologics are introduced into the inner ear are labeled in red, and include both indirect and direct approaches. The indirect approach is through the tympanic membrane (transtympanic or intratympanic) to deposit the therapeutic in the middle ear and allow it to diffuse into the inner ear via the oval and round windows. Direct approaches include delivery into the cochlea through application over or through the round window membrane, through a surgically drilled cochleostomy adjacent to the round window, a fenestra in the bony oval window, or a semicircular canal. Approaches for drug/gene delivery also include combining existing technologies such as cochlear implant electrodes or stapes prosthesis during stapedotomy. (B) Endoscopic view of the anatomy of the human middle ear. The round window niche consists of bony overhang, and the round window is often obscured by a pseudomembrane. M, malleus manubrium; I, incus; P, cochlear promontory; S, stapes; FN, facial nerve; TM, tympanic membrane. Image reproduced with permission from Medscape Drugs \& Diseases

(https://emedicine.medscape.com/), Surgical Treatment of Meniere Disease, 2018, available at: https://emedicine.medscape.com/article/856658-overview.

\section{MODEL SYSTEMS FOR GENE THERAPY}

While optimization and characterization of gene therapy vectors could be done in cell cultures and cochlear explants in vitro, animal studies are required to understand the full panoply of the gene's effects in the inner ear microenvironment. Furthermore, the long-term therapeutic effects, interactions with other organ systems and organ toxicities can only be characterized in a living host. Historically, in vivo gene delivery experiments have been carried out in zebrafish, birds, and rodents. Both zebrafish and birds have well-characterized genomes and robust regenerative capacity in the inner ear sensory epithelium after injury (Daudet et al., 2009; Cotanche and Kaiser, 2010); nevertheless, these nonmammalian model systems are rarely utilized for gene transfer research due to dissimilarities from mammals and humans.

Rodents are the preferred animal models due to their well-characterized genomes, robustness to manipulations, costeffectiveness, and close resemblance to the human inner ear and potential for pre-clinical testing. While the human inner ear is larger than that of rodents, the cochlea of rodents such as guinea pigs can be more accessible due to their unique anatomy where the otic capsule protrudes into the middle ear space and contains thin bony walls (Mikulec et al., 2009; Jawadi et al., 2016). Today, transgenic mouse models capturing various genetic alterations that mimic human disease are well characterized, and mutant mice carrying simultaneous mutations in multiple genes crucial for normal hearing function have been established using CRISPR/Cas-9 technology (Zhang et al., 2018). However, experiments involving delivery of gene therapy using novel AAV systems to the cochlea have been performed largely in neonatal mice (Landegger et al., 2017; Pan et al., 2017). In a mouse model of hereditary deafness through a null mutation in the vesicular glutamate transporter-3 (VGLUT3) responsible for IHC-afferent nerve synaptic transmission, early intervention using AAV-mediated gene delivery at postnatal days $1-3$ led to more efficient and longer duration of hearing recovery than intervention at postnatal day 10 (Akil et al., 2012). While these results are exciting, they may have limited potential for direct clinical correlation and translation to treatments of newborns and adult patients with hearing loss.

Unlike humans, mice are born deaf and begin to hear at approximately 2 weeks of age. Therefore, delivery of therapeutics to neonates would be equivalent to in utero therapy in humans, and thereby pose additional significant technical challenges. In mouse models of progressive hearing loss, gene therapy is typically administered prior to organ of Corti beginning to degenerate in the early postnatal period. By contrast, in many forms of hereditary deafness, there is likely already degeneration of the sensory epithelium and neurons which occurred early in utero, thereby rendering postnatal therapy targeting either hair cells or SGNs futile.

To address these concerns, recent reports utilizing common AAVs, Anc80L65, and $7 \mathrm{~m} 8$ vectors showed efficient transduction of vestibular hair cells in adult mice ranging from P15 to P60, without jeopardizing their cochlear function (Suzuki et al., 2017; Yoshimura et al., 2018; Isgrig et al., 2019). Therefore, future studies should continue to focus on expanding the therapeutic window and developing cochlear gene therapies for adult-stage hearing loss, which would be equivalent to the clinical scenario 
of treating patients with hearing loss months to even years after the initial insult.

Prior to conducting human clinical trials, it is also critically important to test the efficacy and safety of hearing-restoration therapeutics in non-human primates. Inner ear volumes (including soft tissue and fluid) correlate with body mass across species, with an estimated volume of 2.3-2.5, 59.4-63, and 191.1-237 $\mu \mathrm{L}$ for mouse, rhesus monkey, and human, respectively (Ekdale, 2013; Dai et al., 2017). While it is tempting to apply results from mouse studies to human clinical trials, the large discrepancies in inner ear volumes may make such direct extrapolations challenging. Since the human cochlea and labyrinth measures approximately two orders of magnitude larger than that in rodents and only three- to fourfold larger than monkeys, it may be easier to extrapolate successful technical implementation of gene delivery in rhesus monkeys to humans. To achieve this goal, Dai et al. (2017) assessed rhesus audiovestibular functions after mock saline injections via either the oval or round windows. Encouragingly, nearly all animals tolerated the injections with no evidence of toxicity in histological, audiometric, and behavioral analyses (Dai et al., 2017). Based on these results, György et al. (2019) performed the first transmastoid injection of an AAV9 variant via the round window membrane (RWM) in a cynomolgus monkey, which appeared to mediate efficient transduction of both inner and outer hair cells (György et al., 2019). Nevertheless, results were inconsistent as a second monkey showed significantly limited transduction at a lower dose. Future studies utilizing a larger number of animals are required to understand variables such as pre-existing immunity to the AAV vector (Louis Jeune et al., 2013), the dose-dependency of transduction efficiency, and the technical reproducibility of RWM injections in larger mammals (György et al., 2019).

\section{VEHICLES AND TARGETS}

Nearly half of all congenital hearing loss arises from genetic factors, and approximately two-thirds of these are inherited. Most non-syndromic deafness is autosomal recessive (75-90\%) with mutations in GJB2 and SLC26A4 responsible for the majority of cases; most of the remaining cases are inherited in an autosomal dominant pattern, and a small fraction of up to $1.5 \%$ are either X-linked or mitochondrial (Dror and Avraham, 2010; Stamatiou and Stankovic, 2013; Chang, 2015). Compared to gene therapy for acquired hearing loss after mechanical or pharmacological insults, genetic hearing loss poses greater challenges in that successfully regenerated hair cells or neurons would still harbor the causative genetic defect. Therefore, targeted correction of the underlying genetic mutation in all affected cell populations in the cochlea is paramount. Fortunately, with advent in modern sequencing technologies and prenatal testing, it is now becoming possible to detect genetic defects and intervene on them at an earlier stage.

The choice of delivery vector for in vivo gene therapy depends on many factors including the cell type being targeted, route of administration, and therapeutic potency. Delivery platforms can be broadly classified into viral vectors including adenoviruses (AdVs), adeno-associated viruses (AAVs), and retroviruses including lentiviruses (Kiernan and Fekete, 1997; Pietola et al., 2008); versus non-viral vectors such as nanoparticles and exosomes. In theory, viral vectors generally enable more stable and durable expression of the transgene. However, the complex immune response to viruses and the safety of long-term transgene expression are unknown and can be challenging to assess. By contrast, non-viral delivery vehicles are less immunogenic and can be engineered to satisfy the exact therapeutic need. A summary of the viral and non-viral vectors reported in the literature over the last 10 years for in vivo delivery in mature animals is shown in Table 1.

\section{Viral Delivery Agents}

Much of the pre-clinical success in gene therapy for hearing loss is owing to the use of viral vectors to carry payloads into the inner ear. Popular viral vectors include variants of AdV and AAV, both of which have excellent tropism toward a number of cell types in the cochlea and relatively high transduction efficiency in animal models (Akil et al., 2012; Askew et al., 2015). AdVmediated delivery results in transient expression of the transgene, whereas AAV-mediated delivery could lead to long-lasting gene expression. A summary of the advantages and disadvantages of both AdV and AAV vectors for cochlear gene therapy have been the topics of many recent reviews (Husseman and Raphael, 2009; Ahmed et al., 2017; Lustig and Akil, 2018).

Of note, a particular synthetic "ancestral" AAV subtype, Anc80L65, was able to efficiently transduce over $90 \%$ of both inner and outer hair cells at a dose that is two to three times lower than conventional AAV counterparts (Landegger et al., 2017). In a mouse model of Type I Usher syndrome due to mutations in Ush $1 c$ encoding the protein harmonin, wild-type harmonin was successfully delivered into the inner ear after RW membrane injection using the Anc 80 vector. In neonatal P0-1 mice, the delivered gene product was found to be localized to the stereocilia near tip-link insertions on hair cells. Ultrastructural studies using scanning electron microscopy showed normal hair cell morphology and decreased hair cell loss. The treatment not only restored mechanotransduction, but also led to dramatic improvements in complex audiovestibular functions to near wild-type levels for at least 6 months (Pan et al., 2017). These results suggest that virally mediated expression of the transgene can rescue hair cell function if they are present before hair cells degenerate as the animal matures, and such effects could be long-lasting for the duration of development.

Another unresolved question in viral-mediated cochlear gene therapy is whether stable levels of transgene expression can be sustained, and if so, for how long. Since many genes implicated in human deafness are only transiently expressed during normal development, how severe are the negative effects from overexpression? As cells in the sensory epithelium do not typically divide, expression of exogenously transduced genes is not diluted from cell division and could theoretically remain stable over time (Bainbridge et al., 2015). Previous studies in mice have shown stable treatment efficacy with follow-ups of 3-6 months (Akil et al., 2012; Chang et al., 2015; Isgrig et al., 2017; 
TABLE 1 | A summary of the viral vectors recently reported in the literature in the last 10 years for in vivo gene delivery in adult animals.

\begin{tabular}{|c|c|c|c|c|c|c|}
\hline Model (References) & Age & Follow-up & $\operatorname{Sex}(n)$ & Vector(s) & Route & Outcome \\
\hline $\begin{array}{l}\text { Guinea pig (pigmented) } \\
\text { (Shibata et al., 2009) }\end{array}$ & $\mathrm{N} / \mathrm{A}$ & 2 weeks & $M(n=20)$ & BAAV-CMV- $\beta$-actin-GFP & Cochleostomy & $\begin{array}{l}\text { Cochlea: Transduced the supporting cells of both normal and } \\
\text { deafened animals }\end{array}$ \\
\hline $\begin{array}{l}\text { Mouse (CBA/CaJ) (Kilpatrick } \\
\text { et al., 2011) }\end{array}$ & 2-12 months & 5 months & $\operatorname{M\& F}(n=120)$ & AAV2/1-CMV-EGFP (also AAV2/2, 5, 6, 8) & Cochleostomy & $\begin{array}{l}\text { Cochlea: Efficient AAV inoculation (via the scala media) can be } \\
\text { performed in adult mouse ears, with hearing preservation }\end{array}$ \\
\hline $\begin{array}{l}\text { Guinea pig (pigmented) } \\
\text { (Budenz et al., 2015) }\end{array}$ & $1-2$ months & 3 months & $\operatorname{M\& F}(n=46)$ & $\begin{array}{l}\text { AAV2/2-CBA-EGFP, AAV2/2-CBA-NTF3, } \\
\text { AAV2/2-CBA-BDNF }\end{array}$ & Cochleostomy & $\begin{array}{l}\text { Cochlea: Transient elevation in neurotrophin levels can sustain the } \\
\text { cochlear neural substrate in the long term }\end{array}$ \\
\hline $\begin{array}{l}\text { Mouse (CBA/J) (Chien et al., } \\
\text { 2015) }\end{array}$ & $1-2$ months & 4 weeks & $\mathrm{M} \& \mathrm{~F}(n=66)$ & AAV2/8-CMV-GFP & $\begin{array}{l}\text { Cochleostomy } \\
\text { and RWM }\end{array}$ & $\begin{array}{l}\text { Cochlea: Cochleostomy and RWM approach can both be used. } \\
\text { The RWM approach results in less hearing loss vs. cochleostomy }\end{array}$ \\
\hline $\begin{array}{l}\text { Mouse (CBA/CaJ) (Shu et al., } \\
\text { 2016) }\end{array}$ & 6 weeks & 3 months & $\mathrm{M}(n=4)$ & $\begin{array}{l}\text { AAV2/1-CAG-EGFP (also AAV2/2, 5, 6, 6.2, } \\
7,8,9 \text {, rh.8, rh.10, rh.39, rh.43) }\end{array}$ & Cochleostomy & $\begin{array}{l}\text { Cochlea: AAV1, 2, 6.2, 7, 8, 9, rh.39, rh. } 43 \text { transduced IHCs, but } \\
\text { no OHCs - even partial OHC loss. }\end{array}$ \\
\hline $\begin{array}{l}\text { Guinea pig (pigmented) (Lee } \\
\text { et al., 2016) }\end{array}$ & $1-2$ months & 3 weeks & $\mathrm{M} \& \mathrm{~F}(n=26)$ & Ad5-Empty, Ad5-NTF3, AAV2/2-CBA-NTF3 & Cochleostomy & $\begin{array}{l}\text { Cochlea: Hearing threshold shifts, disorganization of peripheral } \\
\text { nerve endings, and synaptic disruption with both vectors. } \\
\text { Elevation of NT3 levels in cochlear fluids can disrupt innervation } \\
\text { and degrade hearing. }\end{array}$ \\
\hline $\begin{array}{l}\text { Mouse (CBA/CaJ) (Suzuki } \\
\text { et al., 2017) }\end{array}$ & 7 weeks & 2 weeks & $\mathrm{M}(n=13)$ & AAV2/Anc80L65-CASI-EGFP-RBG & PSCC & $\begin{array}{l}\text { Cochlea: Successful transduction of all IHCs, majority of OHCs } \\
\text { especially at apex, and } 10 \% \text { of SGNs. Vestibular: Maculae and } \\
\text { cristae transduced. Transduction of many hair cells, all supporting } \\
\text { cells. }\end{array}$ \\
\hline $\begin{array}{l}\text { Mouse (C57BL/6) (Gao et al., } \\
\text { 2018) }\end{array}$ & 6 weeks & 2 weeks & $\operatorname{M\& F}(n=3)$ & Cas9:GFP sgRNA:lipid complex & PSCC & $\begin{array}{l}\text { Cochlea: Target gene disruption at } 25 \pm 2.1 \% \text { efficiency, i.e., } \\
\text { probably applicable to dominant genetic deafness manifested } \\
\text { with late-onset hearing loss }\end{array}$ \\
\hline $\begin{array}{l}\text { Mouse (C57BL/6J and CD1) } \\
\text { (Tao et al., 2018) }\end{array}$ & 8-10 weeks & 7 weeks & $M(n=29)$ & $\begin{array}{l}\text { AAV2/1-CAG-EGFP (also AAV2/2, 6.2, 8, 9, } \\
\text { rh.39, rh.43), } \\
\text { AAV2/Anc80L65-CMV-EGFP-WPRE, } \\
\text { Ad5-CMV-EGFP }\end{array}$ & PSCC & $\begin{array}{l}\text { Cochlea: Most AAVs transduce IHCs efficiently, but are less } \\
\text { efficient at transducing OHCs. Subset of AAVs transduces other } \\
\text { cell types. Canalostomy can be a viable delivery route. }\end{array}$ \\
\hline $\begin{array}{l}\text { Mouse (FVB/N) (Guo et al., } \\
\text { 2018) }\end{array}$ & $5-6$ weeks & 1 week & $\mathrm{F}(n=1)$ & AAV2/8-GFP & PSCC & $\begin{array}{l}\text { Canalostomy is an effective and safe approach to drug delivery } \\
\text { into the inner ears of adult mice. }\end{array}$ \\
\hline $\begin{array}{l}\text { Mouse (C57BL/6) (György } \\
\text { et al., 2019) }\end{array}$ & 4 weeks & 2 weeks & $\mathrm{M} \& \mathrm{~F}(n=2)$ & AAV2/9-PHP.B-CBA-GFP & PSCC & $\begin{array}{l}\text { Cochlea: Almost all IHCs from apex to base transduced, no OHC } \\
\text { transduction. Vestibular: Robust transduction. }\end{array}$ \\
\hline $\begin{array}{l}\text { Mouse (C57BL/6J) (Nist-Lund } \\
\text { et al., 2019) }\end{array}$ & 4 weeks & 7 weeks & $\mathrm{M} \& \mathrm{~F}(n=12)$ & $\begin{array}{l}\text { AAV2/Anc80L65-CMV-TMC1-WPRE, } \\
\text { AAV2/Anc80L65-CMV-TMC2-WPRE, } \\
\text { AAV2/Anc80L65-CMV-TMC1EX1-WPRE, } \\
\text { AAV2/Anc80L65-CMV-EGFP-WPRE }\end{array}$ & RWM & $\begin{array}{l}\text { Cochlea: Gene therapy rescue of sensory function in mature hair } \\
\text { cells. Vestibular: Gene therapy recovery of balance even possible } \\
\text { at mature stages. }\end{array}$ \\
\hline $\begin{array}{l}\text { Mouse (CBA/J) (Isgrig et al., } \\
\text { 2019) }\end{array}$ & $1-6$ months & 4 weeks & $\mathrm{M} \& \mathrm{~F}(n=6)$ & AAV2/7m8-CAG-EGFP & PSCC & $\begin{array}{l}\text { Cochlea: Successful transduction of IHCs }(84.5 \%) \text { and OHCs } \\
(74.9 \%) \text {. Vestibular: Only data for neonatal animals - less efficient } \\
\text { in vestibular organs than cochlea. }\end{array}$ \\
\hline
\end{tabular}


Pan et al., 2017), but few studies have examined the phenotype after this time point.

A related field where rapid progress in gene therapy has occurred in the last decade is the treatment of inherited retinal dystrophies. Importantly, the first successful clinical application of gene therapy involved treatment of inherited blindness (Dalkara et al., 2016). AAV-mediated delivery of RPE65 gene for treatment of Leber's congenital amaurosis received FDA approval in January 2018. This represented the first directly administered clinical gene therapy in the United States that targets a disease caused by mutations in a single gene. Interestingly, long-term studies in patients who underwent gene therapy showed a decline in vision improvement at the 3-year time point, possibly due to the decline in RPE65 expression below a certain threshold level (Bainbridge et al., 2015). Lessons from these studies, along with new data generated in adult animal models, will help better inform the optimal treatment conditions that will maximize successful hearing outcomes.

While equivalent data do not yet exist in human inner ear gene therapy, preclinical animal studies have indicated secondary benefits associated with long-term hearing restoration. A recent study by Nist-Lund et al. (2019) examined the breeding efficiency and survival in a mouse model of recessive TMC1 deafness. Animals injected with AAVs carrying Tmc1 transgene at P1 not only showed improvements in auditory function and balance behavior, but also produced higher number of litters with significantly higher survival rates and near-normal growth rates. Follow-up studies should not only continue to examine the treatment effects of restoring gene expression at longer time points, but also probe the dynamics of gene expression and effects on normal inner ear development.

A potential shortcoming of AAV-mediated gene delivery is the limited cargo size of approximately $4.7-5 \mathrm{~kb}$. As such, delivery of large gene sequences using viral vectors can be challenging. This problem can be partially overcome by dual-AAV systems, where each of the two AAV vector carries a fragment of the large transgene and the two vectors are reassembled to reconstitute the full-length expression cassette in the target cell (Ghosh et al., 2008). Two recent studies used split viral vectors carrying otoferlin cDNA in otoferlin knock-out mice. This led to dual transduction in nearly half of the target IHCs, restoration of protein expression to $30 \%$ of wild-type levels, and partial rescue of auditory function (Akil et al., 2019; Al-Moyed et al., 2019). These results provide proof-of-concept evidence that large gene constructs can be transduced to the cochlear sensory epithelium to at least partially restore hearing in animals. The use of different AAV serotypes and variations in injection timing and dosage may further optimize outcomes in the future.

\section{Non-viral Approaches}

Non-viral vectors, including liposomes, polymeric nanoparticles, and synthetic peptides, offer a powerful alternative strategy for delivery of therapeutics to the inner ear. Compared to viruses, nanomaterials have several distinct advantages. They can be engineered to precisely target a specific cell subpopulation, exhibit low immunogenicity and toxicity, and multiplex in a high-throughput manner to simultaneously address multiple gene targets and pathways. Nanotechnology tools have been employed extensively in fields such as cancer therapeutics to improve the efficacy and accuracy of delivery of small molecules, biologics, and nucleic acid drugs. Nanomaterial-based cochlear delivery systems using liposomes, peptides, or polymers have been developed in recent years and have shown limited success in applications including genetic hearing loss.

Liposomal agents consisting of cationic lipids, which form a bi-layered structure that protects nucleic acids from degradation and antibody neutralization, have enabled cytosolic delivery of nucleic acids into the cytosol for therapeutic applications. Delivery of cre-recombinase and genome editing agents by lipid complexes resulted in $90 \%$ recombination and $20 \%$ genomic editing in neonatal mouse OHCs in vivo (Zuris et al., 2015). Gao et al. (2018) recently developed cationic lipid nanoparticles that encapsulated CRISPR/Cas-9 complexes targeting the $T m c 1^{\text {Bth }}$ allele. In a mouse model of dominant genetic deafness, injection into the cochlea of neonatal mice resulted in moderate reduction of progressive hearing loss and improved hair cell survival in vivo (Gao et al., 2018). Of note, Cas9-single guide RNA was coupled to the cationic lipid formulation, Lipofectamine $2000^{\circledR}$, an unmodified commercially available lipid transfection reagent that does not have any specificity toward a cell subpopulation. As many commercial lipid-based reagents have been shown to mediate significant non-specific modulation of gene expression and cytotoxicity, further work is needed to optimize the efficacy of delivery and minimize off-target effects (Lv et al., 2006). Furthermore, positively charged lipid nanoparticles could evoke a dramatic pro-inflammatory response marked by upregulation of Th1 cytokines, such as IL-2, IFN- $\gamma$, and tumor necrosis factor alpha (TNF- $\alpha$ ), when administered systemically into mice (Kedmi et al., 2010). While therapeutics delivered to the cochlea are thought to remain localized to the inner ear and isolated from systemic circulation by the BLB, any immunostimulatory effects through potential systemic exposure could significantly confound the experimental results. Future studies must carefully assess and minimize the effects from off target immune stimulation while maintaining the efficiency and tissue specificity of delivery. Chemical modifications to lipid molecules could be designed in a rational fashion using computational approaches. Furthermore, high-throughput screening technologies of large combinatorial libraries of lipid-like materials should be utilized to identify in vivo carriers that specifically target hair cells or supporting cells in the organ of Corti (Whitehead et al., 2014).

A distinct advantage of nanoparticle systems is their "tunability" toward a specific delivery need. By modifying the surface chemistry and altering biophysical properties of nanomaterials, one can optimize inner ear bioavailability, reduce clearance, and improve drug targeting. Polymers such as chitosan-glycerophosphate that slowly degrade over time have been customized to enable the sustained-release of dexamethasone and gentamicin into perilymph over several days in mice (Lajud et al., 2015), and deliver a small molecule to protect mice from noise-induced hearing loss (Kayyali et al., 2018). Elsewhere, targeting ligands such as peptides improved the specificity of nanoparticles toward OHCs (Surovtseva et al., 2012; 
Kayyali et al., 2018), spiral ganglion cells (Roy et al., 2010), or cochlear nerve cells (Zhang et al., 2011).

Recently, a new class of peptides carrying short interfering RNAs (siRNA) against TNF- $\alpha$, known as tumor-penetrating nanocomplexes, was used to actively target primary vestibular schwannoma cultures in vitro (Ren et al., 2017). These nanoparticles are based on a new class of tissue-targeting and tumor-penetrating peptides, where the RGD-motif bind to integrins overexpressed on the surface of cancer cells and endothelial cells and subsequently undergo proteolytic processing to unveil a cryptic RXXR domain, which ultimately increases tissue permeability and enables translocation of delivered cargo (Ruoslahti et al., 2010; Liu et al., 2017). By engineering a peptide consisting of a tandem tumor-penetrating and membrane-translocating/siRNA-binding domain, the resulting nanoparticles can penetrate tumor tissue when administered systemically. This platform holds great promise to gain access across the BLB, by increasing the permeability through barriers such as the RWM or oval window. Future work should be directed toward utilizing these novel tumorpenetrating nanomaterials to optimize the in vivo delivery of gene editing or gene silencing agents through the RWM.

\section{SURGERIES FOR GENE THERAPY DELIVERY}

To obtain surgical access to the inner ear in patients, two principal approaches employed clinically include intra- or transtympanic delivery, where the therapeutic is instilled into the middle ear space and allowed to diffuse into the inner ear; and intracochlear delivery, where the drug is introduced directly into the inner ear via the RWM, the oval window, or a semicircular canal (Figure 1A). An effective method of delivery suitable for clinical translation should not require extensive surgical dissection while providing sufficient access to the organ of interest in a minimally invasive fashion. If the patient has any residual hearing, the delivery approach should try to preserve it as much as possible. While intravenous or intraperitoneal injections have been the gold standard for treatment of disease processes such as cancer or bacterial sepsis, the unique BLB surrounding the cochlea may make it difficult for drugs to reach the inner ear. Procedures for local delivery employed in animal models include cochleostomy in the lateral wall of the cochlear basal turn, canalostomy in a semicircular canal, or injection through the RWM; while recent studies have shown general safety of these procedures, they have also highlighted the risk of inner ear injury and permanent SNHL. In this section, we review various routes of application of gene therapy agents with a focus on practical applications in patients.

Intratympanic or transtympanic injections are considered generally low risk procedures to access the middle ear space. In adult patients, this can be done under topical anesthesia in the office, where a small portion of the tympanic membrane is anesthetized and up to $0.7 \mathrm{~mL}$ of drug can be instilled through the perforation into the middle ear. While technically simple to perform, the drug must remain in contact with the RWM for a prolonged period of time to allow enough drug to cross the RWM (Salt and Plontke, 2009). Equilibration and distribution of the drug toward other middle ear spaces or through the Eustachian tube can lead to significant losses, which can be partially overcome by either sustained release or multiple injections over time. The patient may experience minor temporary discomfort associated with the injection, and rare complications may include otorrhea or persistent TM perforation.

Another approach to access the inner ear is directly through the oval window. Normally, the stapes footplate overlies the oval window, and a mucosal epithelium similar to RWM lines the footplate facing the vestibule (King et al., 2013). In animal models, a significant but variable portion of intratympanically administered small molecule drugs were found to enter the scala vestibuli via the stapes footplate. Gadolinium contrast was found at higher levels in the vestibule than scala tympani after middle ear application. Using quantitative volumetric simulations, up to $90 \%$ of gadolinium entered the vestibule through the oval window rather than the RWM in guinea pigs (King et al., 2011). Interestingly for gentamicin, 35\% of the drug entered the perilymph via the stapes and its annular ligament, which resulted in higher drug concentrations in the scala vestibuli than scala tympani due to a slower rate of elimination (Salt et al., 2016). In human cadaveric temporal bones, bisphosphonate introduced via the oval window could reach the apical turn of the cochlea (Kang et al., 2016). In patients with otosclerosis, a bone remodeling disease of the otic capsule and one of the most common causes of acquired hearing loss, access to the vestibule and scala vestibuli is possible during stapedotomy where the stapes footplate is fenestrated. Therefore, by incorporating the drug of interest into the prosthesis, the therapeutic can be released in a controlled fashion into the scala vestibuli. The U.S. gene therapy trial of Ad5.GFAP.Hath1 for the treatment of non-genetic hearing loss delivers the viral vector via a stapedotomy.

A direct method for accessing the RWM can be achieved through a transcanal surgical procedure. With the advent of novel surgical technologies, it is now possible to directly access the round window niche (RWN) through a transcanal approach in the vast majority of patients using an endoscope. Endoscopic ear surgery not only enables superior visualization of complex landmarks within the middle ear (Figure 1B) and mastoid, but also allows specialized, angled instruments to access structures through a transcanal approach (Tarabichi and Kapadia, 2016). In a recent series on round window anatomy, temporal bone studies demonstrated that there is a consistent transcanal angle to reach the RWM perpendicularly through the external auditory canal (EAC), which measured approximately 115-degrees (Fujita et al., 2016). Importantly, one of the key hurdles to reaching the true RWM is obstruction in the RWN by a pseudomembrane, as $72 \%$ of temporal bones showed partial or full obstruction, as well as bony overhangs of median length of $1.77 \mathrm{~mm}$ which limit the direct access to the RWM (Fujita et al., 2016). In this series, nearly a third of specimens required drilling to expose the entire RWM from the EAC. Therefore, in future studies on cochlear drug delivery, it is critical to ensure that the RWN is drilled away or filled with a drug after removal of 
the pseudomembrane so that the drug is in contact with the entirety of the RWM.

The RWM is a three-layered structure lined by squamous epithelium sandwiching a connective tissue layer, which serves as a dynamic barrier that protects the inner ear. A locally administered drug must permeate through the RWM to reach the perilymph within the scala tympani. The permeability of the RWM can be influenced by particle size, charge, and concentration (Goycoolea, 2001), surgical manipulations such as air suctioning nearby (Mikulec et al., 2008), and endotoxins (Ikeda and Morizono, 1988). Conditions such as otitis media that promote middle ear inflammation could also increase RWM permeability through the regulation of cytokines and tight junction proteins (MacArthur et al., 2013). Strategies to artificially enhance transport across the RWM by prolonging the time of exposure to the drug included the use of a gelatin sponge (Jero et al., 2001), thermoreversible hydrogels (Honeder et al., 2015), partial digestion with collagenase (Wang et al., 2012), co-treatment with hyaluronic acid (Shibata et al., 2012), or microperforations (Kelso et al., 2015).

Despite improvements in surgical instrumentation and manipulation of the RWM, the bioavailability of intratympanically administered therapeutics is still remarkably low. In guinea pigs, only $2.5 \%$ of gentamicin was present in the cochlear basal turn when it was irrigated across the RWM for nearly $3 \mathrm{~h}$, and only $0.17 \%$ when the bulla was instilled with the drug for $2 \mathrm{~h}$ (Mikulec et al., 2008). Unfortunately, it is nearly impractical to translate these protocols into clinical use due to the lengthy nature of the protocol. Furthermore, some gene vectors that are designed to efficiently transduce cells of the auditory sensory epithelium in vitro may need to be placed in the scala media to be effective. In CI, a growing area of investigation involves using the implant electrode as a conduit for intracochlear delivery of drugs that may rescue hair cell or neuronal damage for hearing preservation. This could be achieved either through incorporation of the drug into the electrode, or co-administration of the therapeutic at the time of cochleostomy. Implantation of electrode arrays coated with fibroblasts over-expressing brain-derived neurotrophic factor (BDNF) or neurotrophin 3 (NT3) may have a protective effect on SGNs (Rejali et al., 2007; Richardson et al., 2009; Pfingst et al., 2017). Pre-treatment with an anti-apoptotic molecule targeting the MAPK/JNK pathway shortly before electrode insertion could protect sensory epithelium in the organ of Corti from insertion trauma and preserve hearing thresholds in guinea pigs (Eshraghi et al., 2013). CI electrodes capable of eluting dexamethasone have been shown to preserve residual hearing and reduce insertion trauma in animal models (Douchement et al., 2015), which may be through reduction of cochlear fibrosis, suppression of local immune reactivity, and global changes in gene expression (Farhadi et al., 2013; Takumi et al., 2014; Wilk et al., 2016). In addition, a phase II multicenter trial in Europe was recently completed to assess the safety and efficacy of intratympanic steroids during CI (EudraCT Number: 2015-002672-25). Future implants may be optimized through the incorporation of gene delivery vectors targeting sensory cells within the scala tympani or SGNs.

\section{TECHNICAL CONSIDERATIONS}

The human middle ear and inner ear are both exquisitely well-balanced systems so that small perturbations of the microenvironment, such as the introduction of drugs and their respective delivery agents through microsurgical manipulations, could have significant effects on the homeostasis of the entire system. While animal models offer invaluable insight in predicting drug pharmacokinetics and pharmacodynamics for preclinical studies, the translation into clinical testing in patients typically presents with additional challenges owing to differences in the volume and anatomy of inner ear organs. The cochlear aqueduct, a bony channel that projects from the posterior fossa to the cochlear basal turn (Figure 1A), is typically obliterated in humans but widely patent in rodents. The patency of the duct has been attributed to one of the mechanisms by which drugs reach the contralateral ear in the so-called "Schreiner effect" (Stover et al., 2000). Sampling of perilymph via the RWM in rodents could lead to contamination with CSF across the cochlear aqueduct at a significant rate of $0.5-2 \mu \mathrm{L} / \mathrm{min}$ (Hirose et al., 2014). Rodent perilymph samples $>5 \mu \mathrm{L}$ could contain as high as $80 \%$ of CSF in guinea pigs (Salt et al., 2003). Therefore, perforation of the RWM could result in artifactual CSF flow near the basal turn, thereby displacing the drug within minutes of application. This loss can be greater if the site of injection is not completely sealed. As such, one must consider both the technique of injection and any attempts in preventing contamination when evaluating the efficacy of inner ear drug delivery agents.

In addition, the effective concentration of the drug is likely also dependent on the rate and volume of injection into the perilymph. A low rate of injection $(100 \mathrm{~nL} / \mathrm{min})$ over a prolonged period of time is required to drive the drug into perilymph while minimizing traumatic perturbations to the inner ear (Salt and Rask-Andersen, 2004). In guinea pigs, without a proper seal around the injector, leakage of perilymph around the pipette resulted in wash-out of the drug by over $60 \%$ at a rate of approximately $0.09 \mu \mathrm{L} / \mathrm{min}$. This loss could be mitigated by the application of hyaluronate gels over the RWM (Salt et al., 2007). Recently, Salt et al. (2017) investigated the concentration gradient along the scala tympani of a model drug (FITC-dextran) delivered via a pump incorporated into a cochlear implant in guinea pigs. A significant concentration gradient was observed despite a prolonged duration of injection of $24 \mathrm{~h}$, and fluid leakage at the site of cochleostomy could lead to significant drug wash-out (Salt et al., 2017). These results highlight the importance of technical considerations when delivering drugs to the inner ear. In patients, the volume of scala tympani is significantly larger than rodents, and small volume perturbations will likely have less impact on the distribution of drugs. Furthermore, the patency of the cochlear aqueduct is reduced, and CSF pressure is typically negative when the patient is sitting when procedure is performed in the clinic. As a result, displacement of the drug either via CSF influx or leakage through cochleostomy may occur at a substantially lower rate in humans than rodents. Nevertheless, a systematic, quantitative approach is paramount when designing delivery systems for clinical applications to achieve reliable and consistent results. 


\section{FUTURE OUTLOOK}

Since the first human gene therapy treatment in 1990, there have been 2930 gene therapy clinical trials that have been completed, were ongoing, or clinically approved world-wide. Over twothirds of the trials were conducted in the United States (Hanna et al., 2016). There is also a steady increase in the number of newly approved/initiated trials over time, with 163 trials in 2015 alone and nearly 600 more trials since 2015. Adeno-associated viral vectors were utilized in $8.1 \%$ of the trials to date ${ }^{2}$.

Currently, over 20 clinical trials for hearing loss therapies are ongoing in the United States with six potential therapeutic molecules; one of these trials involves gene therapy. There are over 80 active trials in Europe, Asia, and Australia with many more candidate drugs being actively investigated. Preliminary results should be available within the next 2 years, and other platforms are currently being tested in early clinical studies with numerous drugs on the horizon. If early results meet the specified efficacy endpoints, the inclusion criteria will likely see an expansion to other patient populations such as children with early or congenital SNHL. On the contrary, if results from these trials do not meet criteria in the treated population, meticulous follow-up studies must be carried out to determine the cause of failure, which may include patient stratification, route of delivery, and measurement of outcomes. Ultimately, the successful translation of a novel therapeutic from the laboratory bench to the otology clinic or operating room require a multidisciplinary approach through the collaboration between molecular biologists, virologists, chemists, biomedical engineers, otologic surgeons, government, and business leaders.

As treatments for hearing loss become more personalized, more gene targets that are amenable to targeting will be uncovered. Gene therapy can involve not only the insertion of a transgene through efficient viral transduction, but also silencing of a dominant negative allele through miRNA or siRNAs. Off-target effects will be minimized through enhancing the specificity of therapy. Next-generation CRISPR-Cas systems will be harnessed for precise disruption and editing of DNA or RNA for each patient.

The efficacy and specificity of the gene delivery agent will also likely improve. Engineering of the capsid proteins may further improve viral tropism so that viruses can be tuned to preferentially target the cell subpopulation in the sensory epithelium while minimizing off-target effects. Incorporating cell type-specific promoters will enable the precise targeting and gene expression in cellular subpopulations within the cochlea. Simultaneous testing in animal models and humans will highlight differences between the two, and obstacles such as viral immunogenicity can be addressed. Active, or membranepenetrating delivery platforms may provide a method to traverse cellular tight junctions (Ruoslahti, 2017). This may significantly enhance the bioavailability of the drug if hearing is not impaired. Finally, deployment of "smart," on-demand drug delivery systems may further improve drug availability by fine-tuning the release kinetics and minimizing drug loss.

\footnotetext{
${ }^{2}$ http://www.abedia.com/wiley/vectors.php
}

Future surgical innovations and technologies could help better detect electrophysiological changes in the inner ear associated with therapeutic interventions. Electrocochleography studies could provide insight into cochlear changes in real time during an implant and predict hearing thresholds postoperatively, and may be utilized to monitor inner ear physiology and minimize the risk of cochlear damage during electrode insertion or infusion of gene delivery vectors (Dalbert et al., 2018). More sophisticated electrodes are being developed to incorporate neuroprotective substances and drugs. The incorporation of microsurgical and robotic tools in otologic and neurotologic surgeries could make surgeries more precise, less traumatic, and customized to each patient's unique anatomy.

Current assessments of hearing levels largely rely on indirect measurements such as audiograms, otoacoustic emissions, or auditory brainstem responses. Post mortem temporal bone histology has been the gold standard to visualize the pathology underlying hearing loss. However, the advent of intracochlear imaging has been challenging due to the complex threedimensional anatomy and complete encasement in the bony otic capsule. Future development of tools to non- or minimally invasively assess the function of the inner ear at a cellular resolution will likely revolutionize the way hearing loss is diagnosed and treated. Optical coherence tomography (Dong et al., 2018), micro optical coherence tomography (Iyer et al., 2016), and two photon fluorescence imaging (Yang et al., 2013) have the potential to visualize cochlear microanatomy at high resolution, thus overcoming limitations of bright field endoscopy (Chole, 2015). While synchrotron radiation phase contrast imaging reveals intracochlear microanatomy through the encased bone, future work is needed to minimize radiation energy before this technology can be translated to the clinic (Iyer et al., 2018). In the meantime, light sheet microscopy (Santi, 2011) and incorporation of calcium- or potassium-based molecular imaging markers may shed additional light on the integrity and function of hair cells and other cochlear cells in real time. Together, by taking an interdisciplinary approach and combining new genomic data, better bioengineering tools, and innovative surgical approaches, clinical success for gene therapy for SNHL and inner ear disease is not far away.

\section{AUTHOR CONTRIBUTIONS}

YR, LDL, and KMS designed the study and conducted the research and literature search. YR and KMS prepared the manuscript. All authors edited and approved the final manuscript.

\section{FUNDING}

This work was supported by grants from the National Institute of Health/National Institute on Deafness and Other Communication Disorders grant R01DC015824, the Nancy Sayles Day Foundation, the Lauer Tinnitus Research Center, the Zwanzger Foundation, the Barnes Foundation, and the Sheldon and Dorothea Buckler (KMS). 


\section{REFERENCES}

Ahmed, H., Shubina-Oleinik, O., and Holt, J. R. (2017). Emerging gene therapies for genetic hearing loss. J. Assoc. Res. Otolaryngol. 18, 649-670. doi: 10.1007/ s10162-017-0634-638

Akil, O., Dyka, F., Calvet, C., Emptoz, A., Lahlou, G., Nouaille, S., et al. (2019). Dual AAV-mediated gene therapy restores hearing in a DFNB9 mouse model. Proc. Natl. Acad. Sci. U.S.A. 116, 4496-4501. doi: 10.1073/pnas.1817537116

Akil, O., Seal, R. P., Burke, K., Wang, C., Alemi, A., During, M., et al. (2012). Restoration of hearing in the VGLUT3 knockout mouse using virally mediated gene therapy. Neuron 75, 283-293. doi: 10.1016/j.neuron.2012.05.019

Al-Moyed, H., Cepeda, A. P., Jung, S., Moser, T., Kügler, S., and Reisinger, E. (2019). A dual-AAV approach restores fast exocytosis and partially rescues auditory function in deaf otoferlin knock-out mice. EMBO Mol. Med. 11:e9396. doi: 10.15252/emmm.201809396

Askew, C., Rochat, C., Pan, B., Asai, Y., Ahmed, H., Child, E., et al. (2015). Tmc gene therapy restores auditory function in deaf mice. Sci. Transl. Med. 7:295ra108. doi: 10.1126/scitranslmed.aab1996

Axelsson, A. (1988). Comparative anatomy of cochlear blood vessels. Am. J. Otolaryngol. 9, 278-290. doi: 10.1016/s0196-0709(88)80036-x

Bainbridge, J. W. B., Mehat, M. S., Sundaram, V., Robbie, S. J., Barker, S. E., Ripamonti, C., et al. (2015). Long-term effect of gene therapy on Leber's congenital amaurosis. N. Engl. J. Med. 372, 1887-1897. doi: 10.1056/ NEJMoa1414221

Banks, W. A. (2016). From blood-brain barrier to blood-brain interface: new opportunities for CNS drug delivery. Nat. Rev. Drug Discov. 15, 275-292. doi: $10.1038 /$ nrd.2015.21

Budenz, C. L., Wong, H. T., Swiderski, D. L., Shibata, S. B., Pfingst, B. E., and Raphael, Y. (2015). Differential effects of AAV.BDNF and AAV.Ntf3 in the deafened adult guinea pig ear. Sci. Rep. 5:8619. doi: 10.1038/srep08619

Chang, K. W. (2015). Genetics of hearing loss-nonsyndromic. Otolaryngol. Clin. North Am. 48, 1063-1072. doi: 10.1016/j.otc.2015.06.005

Chang, Q., Wang, J., Li, Q., Kim, Y., Zhou, B., Wang, Y., et al. (2015). Virally mediated Kcnql gene replacement therapy in the immature scala media restores hearing in a mouse model of human Jervell and Lange-Nielsen deafness syndrome. EMBO Mol. Med. 7, 1077-1086. doi: 10.15252/emmm.20140 4929

Chien, W. W., McDougald, D. S., Roy, S., Fitzgerald, T. S., and Cunningham, L. L. (2015). Cochlear gene transfer mediated by adeno-associated virus: comparison of two surgical approaches. Laryngoscope 125, 2557-2564. doi: 10.1002/lary. 25317

Chole, R. A. (2015). Endoscopic view of the scala tympani. Otol. Neurotol. 36, e97-e98. doi: 10.1097/MAO.0000000000000365

Cotanche, D. A., and Kaiser, C. L. (2010). Hair cell fate decisions in cochlear development and regeneration. Hear. Res. 266, 18-25. doi: 10.1016/j.heares. 2010.04.012

Dai, C., Lehar, M., Sun, D. Q., Rvt, L. S., Carey, J. P., MacLachlan, T., et al. (2017). Rhesus cochlear and vestibular functions are preserved after inner ear injection of saline volume sufficient for gene therapy delivery. J. Assoc. Res. Otolaryngol. 18, 601-617. doi: 10.1007/s10162-017-0628-626

Dalbert, A., Pfiffner, F., Hoesli, M., Koka, K., Veraguth, D., Roosli, C., et al. (2018). Assessment of cochlear function during cochlear implantation by extra- and intracochlear electrocochleography. Front. Neurosci. 12:18. doi: 10.3389/fnins. 2018.00018

Dalkara, D., Goureau, O., Marazova, K., and Sahel, J.-A. (2016). Let there be light: gene and cell therapy for blindness. Hum. Gene Ther. 27, 134-147. doi: 10.1089/hum.2015.147

Daudet, N., Gibson, R., Shang, J., Bernard, A., Lewis, J., and Stone, J. (2009). Notch regulation of progenitor cell behavior in quiescent and regenerating auditory epithelium of mature birds. Dev. Biol. 326, 86-100. doi: 10.1016/j.ydbio.2008. 10.033

Devare, J., Gubbels, S., and Raphael, Y. (2018). Outlook and future of inner ear therapy. Hear. Res. 368, 127-135. doi: 10.1016/j.heares.2018.05.009

Dong, W., Xia, A., Raphael, P. D., Puria, S., Applegate, B., and Oghalai, J. S. (2018). Organ of Corti vibration within the intact gerbil cochlea measured by volumetric optical coherence tomography and vibrometry. J. Neurophysiol. 120, 2847-2857. doi: 10.1152/jn.00702.2017
Douchement, D., Terranti, A., Lamblin, J., Salleron, J., Siepmann, F., Siepmann, J., et al. (2015). Dexamethasone eluting electrodes for cochlear implantation: effect on residual hearing. Cochlear Implants Int. 16, 195-200. doi: 10.1179/ 1754762813Y.0000000053

Dror, A. A., and Avraham, K. B. (2010). Hearing impairment: a panoply of genes and functions. Neuron 68, 293-308. doi: 10.1016/j.neuron.2010.10.011

Ekdale, E. G. (2013). Comparative anatomy of the Bony Labyrinth (Inner Ear) of placental mammals. PLoS One 8:e66624. doi: 10.1371/journal.pone.0066624

Eshraghi, A. A., Gupta, C., Van De Water, T. R., Bohorquez, J. E., Garnham, C., Bas, E., et al. (2013). Molecular mechanisms involved in cochlear implantation trauma and the protection of hearing and auditory sensory cells by inhibition of c-jun-N-terminal kinase signaling. Laryngoscope 123, S1-S14. doi: 10.1002/ lary. 23902

Farhadi, M., Jalessi, M., Salehian, P., Ghavi, F. F., Emamjomeh, H., Mirzadeh, H., et al. (2013). Dexamethasone eluting cochlear implant: histological study in animal model. Cochlear Implants Int. 14, 45-50. doi: 10.1179/1754762811Y. 0000000024

Fujita, T., Shin, J. E., Cunnane, M., Fujita, K., Henein, S., Psaltis, D., et al. (2016). Surgical anatomy of the human round window region: implication for cochlear endoscopy through the external auditory canal. Otol. Neurotol. 37, 1189-1194. doi: 10.1097/MAO.0000000000001074

Gao, X., Tao, Y., Lamas, V., Huang, M., Yeh, W.-H., Pan, B., et al. (2018). Treatment of autosomal dominant hearing loss by in vivo delivery of genome editing agents. Nature 553, 217-221. doi: 10.1038/nature25164

Ghosh, A., Yue, Y., Lai, Y., and Duan, D. (2008). A hybrid vector system expands adeno-associated viral vector packaging capacity in a transgene-independent manner. Mol. Therapy 16, 124-130. doi: 10.1038/sj.mt.6300322

Gorlin, R. J., Gorlin, R. J., Toriello, H. V., and Cohen, M. M. (1995). Hereditary Hearing Loss and Its Syndromes. New York, NY: Oxford University Press.

Goycoolea, M. V. (2001). Clinical aspects of round window membrane permeability under normal and pathological conditions. Acta Oto Laryngologica 121, 437-447. doi: 10.1080/000164801300366552

Guo, J.-Y., He, L., Qu, T.-F., Liu, Y.-Y., Liu, K., Wang, G.-P., et al. (2018). Canalostomy as a surgical approach to local drug delivery into the inner ears of adult and neonatal mice*. J. Vis. Exp. e57351. doi: 10.3791/57351

György, B., Meijer, E. J., Ivanchenko, M. V., Tenneson, K., Emond, F., Hanlon, K. S., et al. (2019). Gene transfer with AAV9-PHP.B rescues hearing in a mouse model of usher syndrome $3 \mathrm{~A}$ and transduces hair cells in a non-human primate. Mol. Ther. Methods Clin. Dev. 13, 1-13. doi: 10.1016/j.omtm.2018.11.003

Hanna, E., Rémuzat, C., Auquier, P., and Toumi, M. (2016). Advanced therapy medicinal products: current and future perspectives. J. Mark Access Health Policy 4:31036. doi: 10.3402/jmahp.v4.31036

Hirose, K., Hartsock, J. J., Johnson, S., Santi, P., and Salt, A. N. (2014). Systemic lipopolysaccharide compromises the blood-labyrinth barrier and increases entry of serum fluorescein into the perilymph. J. Assoc. Res. Otolaryngol. 15, 707-719. doi: 10.1007/s10162-014-0476-476

Hirose, K., and Li, S.-Z. (2019). The role of monocytes and macrophages in the dynamic permeability of the blood-perilymph barrier. Hear. Res. 374, 49-57. doi: 10.1016/j.heares.2019.01.006

Honeder, C., Landegger, L. D., Engleder, E., Gabor, F., Plasenzotti, R., Plenk, H., et al. (2015). Effects of intraoperatively applied glucocorticoid hydrogels on residual hearing and foreign body reaction in a guinea pig model of cochlear implantation. Acta Oto Laryngol. 135, 313-319. doi: 10.3109/00016489.2014. 986758

Husseman, J., and Raphael, Y. (2009). Gene therapy in the inner ear using adenovirus vectors. Adv. Otorhinolaryngol. 66, 37-51. doi: 10.1159/0002 18206

Ikeda, K., and Morizono, T. (1988). Changes of the permeability of round window membrane in otitis media. Arch. Otolaryngol. Head Neck Surg. 114, 895-897. doi: 10.1001/archotol.1988.01860200079023

Isgrig, K., McDougald, D. S., Zhu, J., Wang, H. J., Bennett, J., and Chien, W. W. (2019). AAV2.7 $m 8$ is a powerful viral vector for inner ear gene therapy. Nat. Commun. 10:427. doi: 10.1038/s41467-018-08243-8241

Isgrig, K., Shteamer, J. W., Belyantseva, I. A., Drummond, M. C., Fitzgerald, T. S., Vijayakumar, S., et al. (2017). Gene therapy restores balance and auditory functions in a mouse model of usher syndrome. Mol. Ther. 25, 780-791. doi: 10.1016/j.ymthe.2017.01.007 
Iyer, J. S., Batts, S. A., Chu, K. K., Sahin, M. I., Leung, H. M., Tearney, G. J., et al. (2016). Micro-optical coherence tomography of the mammalian cochlea. Sci. Rep. 6:33288. doi: 10.1038/srep33288

Iyer, J. S., Zhu, N., Gasilov, S., Ladak, H. M., Agrawal, S. K., and Stankovic, K. M. (2018). Visualizing the 3D cytoarchitecture of the human cochlea in an intact temporal bone using synchrotron radiation phase contrast imaging. Biomed. Opt. Express 9, 3757-3767. doi: 10.1364/BOE.9.003757

Jawadi, Z., Applegate, B. E., and Oghalai, J. S. (2016). Optical coherence tomography to measure sound-induced motions within the mouse organ of corti in vivo. Methods Mol. Biol. 1427, 449-462. doi: 10.1007/978-1-49393615-1_24

Jero, J., Mhatre, A. N., Tseng, C. J., Stern, R. E., Coling, D. E., Goldstein, J. A., et al. (2001). Cochlear gene delivery through an intact round window membrane in mouse. Hum. Gene Ther. 12, 539-548. doi: 10.1089/104303401300042465

Kang, W. S., Nguyen, K., McKenna, C. E., Sewell, W. F., McKenna, M. J., and Jung, D. H. (2016). Intracochlear drug delivery through the oval window in fresh cadaveric human temporal bones. Otol. Neurotol. 37, 218-222. doi: 10.1097/ MAO.0000000000000964

Kayyali, M. N., Wooltorton, J. R. A., Ramsey, A. J., Lin, M., Chao, T. N., Tsourkas, A., et al. (2018). A novel nanoparticle delivery system for targeted therapy of noise-induced hearing loss. J. Control. Release 279, 243-250. doi: 10.1016/j. jconrel.2018.04.028

Kedmi, R., Ben-Arie, N., and Peer, D. (2010). The systemic toxicity of positively charged lipid nanoparticles and the role of Toll-like receptor 4 in immune activation. Biomaterials 31, 6867-6875. doi: 10.1016/j.biomaterials.2010.05.027

Kelso, C. M., Watanabe, H., Wazen, J. M., Bucher, T., Qian, Z. J., Olson, E. S., et al. (2015). Microperforations significantly enhance diffusion across round window membrane. Otol. Neurotol. 36, 694-700. doi: 10.1097/MAO.0000000000000629

Kiernan, A. E., and Fekete, D. M. (1997). In vivo gene transfer into the embryonic inner ear using retroviral vectors. Audiol. Neurotol. 2, 12-24. doi: 10.1159/ 000259226

Kilpatrick, L. A., Li, Q., Yang, J., Goddard, J. C., Fekete, D. M., and Lang, H. (2011). Adeno-associated virus-mediated gene delivery into the scala media of the normal and deafened adult mouse ear. Gene Ther. 18, 569-578. doi: 10.1038/gt.2010.175

King, E. B., Salt, A. N., Eastwood, H. T., and O'Leary, S. J. (2011). Direct entry of gadolinium into the vestibule following intratympanic applications in guinea pigs and the influence of cochlear implantation. J. Assoc. Res. Otolaryngol. 12, 741-751. doi: 10.1007/s10162-011-0280-285

King, M. D., Alleyne, C. H. J., and Dhandapani, K. M. (2013). TNF-alpha receptor antagonist, R-7050, improves neurological outcomes following intracerebral hemorrhage in mice. Neurosci. Lett. 542, 92-96. doi: 10.1016/j.neulet.2013. 02.051

Kopke, R., Allen, K. A., Henderson, D., Hoffer, M., Frenz, D., and Van de Water, T. (1999). A radical demise. Toxins and trauma share common pathways in hair cell death. Ann. N. Y. Acad. Sci. 884, 171-191. doi: 10.1111/j.1749-6632.1999. tb08641.x

Kwon, E. J., Skalak, M., Lo Bu, R., and Bhatia, S. N. (2016). Neuron-targeted nanoparticle for siRNA delivery to traumatic brain injuries. ACS Nano 10, 7926-7933. doi: 10.1021/acsnano.6b03858

Lajud, S. A., Nagda, D. A., Qiao, P., Tanaka, N., Civantos, A., Gu, R., et al. (2015). A novel chitosan-hydrogel-based nanoparticle delivery system for local inner ear application. Otol. Neurotol. 36, 341-347. doi: 10.1097/MAO. 0000000000000445

Landegger, L. D., Pan, B., Askew, C., Wassmer, S. J., Gluck, S. D., Galvin, A., et al. (2017). A synthetic AAV vector enables safe and efficient gene transfer to the mammalian inner ear. Nat. Biotechnol. 35, 280-284. doi: 10.1038/nbt.3781

Lee, M. Y., Kurioka, T., Nelson, M. M., Prieskorn, D. M., Swiderski, D. L., Takada, Y., et al. (2016). Viral-mediated Ntf3 overexpression disrupts innervation and hearing in nondeafened guinea pig cochleae. Mol. Ther. Methods Clin. Dev. 3:16052. doi: $10.1038 / \mathrm{mtm} .2016 .52$

Lim, D. J., and Hussl, B. (1975). Macromolecular transport by the middle ear and its lymphatic system. Acta Oto Laryngol. 80, 19-31. doi: 10.3109/ 00016487509121296

Lin, F. R., Thorpe, R., Gordon-Salant, S., and Ferrucci, L. (2011). Hearing loss prevalence and risk factors among older adults in the United States. J. Gerontol. A Biol. Sci. Med. Sci. 66A, 582-590. doi: 10.1093/gerona/glr002
Liu, X., Lin, P., Perrett, I., Lin, J., Liao, Y.-P., Chang, C. H., et al. (2017). Tumorpenetrating peptide enhances transcytosis of silicasome-based chemotherapy for pancreatic cancer. J. Clin. Invest. 127, 2007-2018. doi: 10.1172/JCI92284

Louis Jeune, V., Joergensen, J. A., Hajjar, R. J., and Weber, T. (2013). Pre-existing anti-adeno-associated virus antibodies as a challenge in AAV gene therapy. Hum. Gene. Ther. Methods 24, 59-67. doi: 10.1089/hgtb.2012.243

Lustig, L., and Akil, O. (2018). Cochlear gene therapy. Cold Spring Harb. Perspect. Med. a033191. doi: 10.1101/cshperspect.a033191

Lv, H., Zhang, S., Wang, B., Cui, S., and Yan, J. (2006). Toxicity of cationic lipids and cationic polymers in gene delivery. J. Control. Release 114, 100-109. doi: 10.1016/j.jconrel.2006.04.014

MacArthur, C. J., Hausman, F., Kempton, J. B., Sautter, N., and Trune, D. R. (2013). Inner ear tissue remodeling and ion homeostasis gene alteration in murine chronic otitis media. Otol. Neurotol. 34, 338-346. doi: 10.1097/MAO. 0b013e31827b4d0a

Manoussaki, D., Dimitriadis, E. K., and Chadwick, R. S. (2006). Cochlea's graded curvature effect on low frequency waves. Phys. Rev. Lett. 96:088701. doi: 10. 1103/PhysRevLett.96.088701

Mikulec, A. A., Hartsock, J. J., and Salt, A. N. (2008). Permeability of the round window membrane is influenced by the composition of applied drug solutions and by common surgical procedures. Otol. Neurotol. 29, 1020-1026. doi: 10. 1097/MAO.0b013e31818658ea

Mikulec, A. A., Plontke, S. K., Hartsock, J. J., and Salt, A. N. (2009). Entry of substances into perilymph through the bone of the otic capsule after intratympanic applications in guinea pigs: implications for local drug delivery in humans. Otol. Neurotol. 30, 131-138. doi: 10.1097/mao.0b013e318191bff8

Nist-Lund, C. A., Pan, B., Patterson, A., Asai, Y., Chen, T., Zhou, W., et al. (2019). Improved TMC1 gene therapy restores hearing and balance in mice with genetic inner ear disorders. Nat. Commun. 10:236. doi: 10.1038/s41467-018-08264-w

Pan, B., Askew, C., Galvin, A., Heman-Ackah, S., Asai, Y., Indzhykulian, A. A., et al. (2017). Gene therapy restores auditory and vestibular function in a mouse model of Usher syndrome type 1c. Nat. Biotechnol. 35, 264-272. doi: 10.1038/ nbt. 3801

Pardridge, W. M. (2016). CSF, blood-brain barrier, and brain drug delivery. Expert. Opin. Drug Deliv. 13, 963-975. doi: 10.1517/17425247.2016.1171315

Pfingst, B. E., Colesa, D. J., Swiderski, D. L., Hughes, A. P., Strahl, S. B., Sinan, M., et al. (2017). Neurotrophin gene therapy in deafened ears with cochlear implants: long-term effects on nerve survival and functional measures. J. Assoc. Res. Otolaryngol. 18, 731-750. doi: 10.1007/s10162-017-0633-639

Pietola, L., Aarnisalo, A. A., Joensuu, J., Pellinen, R., Wahlfors, J., and Jero, J. (2008). HOX-GFP and WOX-GFP lentivirus vectors for inner ear gene transfer. Acta Oto Laryngol. 128, 613-620. doi: 10.1080/00016480701663409

Rejali, D., Lee, V. A., Abrashkin, K. A., Humayun, N., Swiderski, D. L., and Raphael, Y. (2007). Cochlear implants and ex vivo BDNF gene therapy protect spiral ganglion neurons. Hear. Res. 228, 180-187. doi: 10.1016/j.heares.2007.02.010

Ren, Y., Cheung, H. W., von Maltzhan, G., Agrawal, A., Cowley, G. S., Weir, B. A., et al. (2012). Targeted tumor-penetrating siRNA nanocomplexes for credentialing the ovarian cancer oncogene ID4. Sci. Transl. Med. 4:147ra112. doi: 10.1126/scitranslmed.3003778

Ren, Y., Sagers, J. E., Landegger, L. D., Bhatia, S. N., and Stankovic, K. M. (2017). Tumor-penetrating delivery of siRNA against TNF $\alpha$ to human vestibular schwannomas. Sci. Rep. 7:12922. doi: 10.1038/s41598-017-13032-13039

Richardson, R. T., Wise, A. K., Thompson, B. C., Flynn, B. O., Atkinson, P. J., Fretwell, N. J., et al. (2009). Polypyrrole-coated electrodes for the delivery of charge and neurotrophins to cochlear neurons. Biomaterials 30, 2614-2624. doi: 10.1016/j.biomaterials.2009.01.015

Roy, S., Johnston, A. H., Newman, T. A., Glueckert, R., Dudas, J., Bitsche, M., et al. (2010). Cell-specific targeting in the mouse inner ear using nanoparticles conjugated with a neurotrophin-derived peptide ligand: potential tool for drug delivery. Int. J. Pharm. 390, 214-224. doi: 10.1016/j.ijpharm.2010.02.003

Rubel, E. W., and Fritzsch, B. (2002). Auditory system development: primary auditory neurons and their targets. Annu. Rev. Neurosci. 25, 51-101. doi: 10. 1146/annurev.neuro.25.112701.142849

Ruoslahti, E. (2017). Tumor penetrating peptides for improved drug delivery. Adv. Drug Deliv. Rev. 110-111, 3-12. doi: 10.1016/j.addr.2016.03.008

Ruoslahti, E., Bhatia, S. N., and Sailor, M. J. (2010). Targeting of drugs and nanoparticles to tumors. J. Cell Biol. 188, 759-768. doi: 10.1083/jcb.200910104 
Salt, A., Hartsock, J., Gill, R., Smyth, D., Kirk, J., and Verhoeven, K. (2017). Perilymph pharmacokinetics of marker applied through a cochlear implant in guinea pigs. PLoS One 12:e0183374. doi: 10.1371/journal.pone.0183374

Salt, A. N., Hartsock, J. J., Gill, R. M., King, E., Kraus, F. B., and Plontke, S. K. (2016). Perilymph pharmacokinetics of locally-applied gentamicin in the guinea pig. Hear. Res. 342, 101-111. doi: 10.1016/j.heares.2016.10.003

Salt, A. N., and Hirose, K. (2018). Communication pathways to and from the inner ear and their contributions to drug delivery. Hear. Res. 362, 25-37. doi: 10.1016/j.heares.2017.12.010

Salt, A. N., Kellner, C., and Hale, S. (2003). Contamination of perilymph sampled from the basal cochlear turn with cerebrospinal fluid. Hear. Res. 182, 24-33. doi: 10.1016/s0378-5955(03)00137-0

Salt, A. N., and Plontke, S. K. (2009). Principles of local drug delivery to the inner ear. Audiol. Neurotol. 14, 350-360. doi: 10.1159/000241892

Salt, A. N., and Rask-Andersen, H. (2004). Responses of the endolymphatic sac to perilymphatic injections and withdrawals: evidence for the presence of a one-way valve. Hear. Res. 191, 90-100. doi: 10.1016/j.heares.2003.12.018

Salt, A. N., Sirjani, D. B., Hartsock, J. J., Gill, R. M., and Plontke, S. K. (2007). Marker retention in the cochlea following injections through the round window membrane. Hear. Res. 232, 78-86. doi: 10.1016/j.heares.2007.06.010

Santi, P. A. (2011). Light sheet fluorescence microscopy: a review. J. Histochem. Cytochem. 59, 129-138. doi: 10.1369/0022155410394857

Sheffield, A. M., and Smith, R. J. H. (2018). The epidemiology of deafness. Cold Spring Harb Perspect Med. a033258. doi: 10.1101/cshperspect.a033258 [Epub ahead of print].

Shibata, S. B., Cortez, S. R., Wiler, J. A., Swiderski, D. L., and Raphael, Y. (2012). Hyaluronic acid enhances gene delivery into the cochlea. Hum. Gene Ther. 23, 302-310. doi: 10.1089/hum.2011.086

Shibata, S. B., Di Pasquale, G., Cortez, S. R., Chiorini, J. A., and Raphael, Y. (2009). Gene transfer using bovine adeno-associated virus in the guinea pig cochlea. Gene Ther. 16, 990-997. doi: 10.1038/gt.2009.57

Shu, Y., Tao, Y., Wang, Z., Tang, Y., Li, H., Dai, P., et al. (2016). Identification of adeno-associated viral vectors that target neonatal and adult mammalian inner ear cell subtypes. Hum. Gene Ther. 27, 687-699. doi: 10.1089/hum. 2016.053

Smith, N. M., Gachulincova, I., Ho, D., Bailey, C., Bartlett, C. A., Norret, M., et al. (2016). An unexpected transient breakdown of the blood brain barrier triggers passage of large intravenously administered nanoparticles. Sci. Rep. 6:22595. doi: $10.1038 /$ srep22595

Stamatiou, G. A., and Stankovic, K. M. (2013). A comprehensive network and pathway analysis of human deafness genes. Otol. Neurotol. 34, 961-970. doi: 10.1097/MAO.0b013e3182898272

Stover, T., Yagi, M., and Raphael, Y. (2000). Transduction of the contralateral ear after adenovirus-mediated cochlear gene transfer. Gene Ther. 7, 377-383. doi: $10.1038 /$ sj.gt.3301108

Surovtseva, E. V., Johnston, A. H., Zhang, W., Zhang, Y., Kim, A., Murakoshi, M., et al. (2012). Prestin binding peptides as ligands for targeted polymersome mediated drug delivery to outer hair cells in the inner ear. Int. J. Pharm. 424, 121-127. doi: 10.1016/j.ijpharm.2011.12.042

Suzuki, J., Hashimoto, K., Xiao, R., Vandenberghe, L. H., and Liberman, M. C. (2017). Cochlear gene therapy with ancestral AAV in adult mice: complete transduction of inner hair cells without cochlear dysfunction. Sci. Rep. 7:45524. doi: $10.1038 /$ srep45524
Suzuki, M., Yamasoba, T., Ishibashi, T., Miller, J. M., and Kaga, K. (2002). Effect of noise exposure on blood-labyrinth barrier in guinea pigs. Hear. Res. 164, 12-18. doi: 10.1016/s0378-5955(01)00397-5

Takumi, Y., Nishio, S.-Y., Mugridge, K., Oguchi, T., Hashimoto, S., Suzuki, N., et al. (2014). Gene expression pattern after insertion of dexamethasone-eluting electrode into the guinea pig cochlea. PLoS One 9:e110238. doi: 10.1371/journal. pone.0110238

Tao, Y., Huang, M., Shu, Y., Ruprecht, A., Wang, H., Tang, Y., et al. (2018). Delivery of adeno-associated virus vectors in adult mammalian inner-ear cell subtypes without auditory dysfunction. Hum. Gene Ther. 29, 492-506. doi: 10.1089/hum. 2017.120

Tarabichi, M., and Kapadia, M. (2016). Principles of endoscopic ear surgery. Curr. Opin. Otolaryngol. Head Neck Surg. 24, 382-387. doi: 10.1097/MOO. 0000000000000296

Wang, H., Murphy, R., Taaffe, D., Yin, S., Xia, L., Hauswirth, W. W., et al. (2012). Efficient cochlear gene transfection in guinea-pigs with adeno-associated viral vectors by partial digestion of round window membrane. Gene Ther. 19, 255-263. doi: 10.1038/gt.2011.91

Whitehead, K. A., Dorkin, J. R., Vegas, A. J., Chang, P. H., Veiseh, O., Matthews, J., et al. (2014). Degradable lipid nanoparticles with predictable in vivo siRNA delivery activity. Nat. Commun. 5:4277. doi: 10.1038/ncomms5277

Wilk, M., Hessler, R., Mugridge, K., Jolly, C., Fehr, M., Lenarz, T., et al. (2016). Impedance changes and fibrous tissue growth after cochlear implantation are correlated and can be reduced using a Dexamethasone eluting electrode. PLoS One 11:e0147552. doi: 10.1371/journal.pone.0147552

Yang, X., Pu, Y., Hsieh, C.-L., Ong, C. A., Psaltis, D., and Stankovic, K. M. (2013). Two-photon microscopy of the mouse cochlea in situ for cellular diagnosis. J. Biomed. Opt. 18:31104. doi: 10.1117/1.JBO.18.3.031104

Yoshimura, H., Shibata, S. B., Ranum, P. T., and Smith, R. J. H. (2018). Enhanced viral-mediated cochlear gene delivery in adult mice by combining canal fenestration with round window membrane inoculation. Sci. Rep. 8:2980. doi: 10.1038/s41598-018-21233-z

Zhang, H., Pan, H., Zhou, C., Wei, Y., Ying, W., Li, S., et al. (2018). Simultaneous zygotic inactivation of multiple genes in mouse through CRISPR/Cas9mediated base editing. Development 145:dev168906. doi: 10.1242/dev.168906

Zhang, W., Zhang, Y., Löbler, M., Schmitz, K.-P., Ahmad, A., Pyykkö, I., et al. (2011). Nuclear entry of hyperbranched polylysine nanoparticles into cochlear cells. Int. J. Nanomed. 6, 535-546. doi: 10.2147/IJN.S16973

Zuris, J. A., Thompson, D. B., Shu, Y., Guilinger, J. P., Bessen, J. L., Hu, J. H., et al. (2015). Cationic lipid-mediated delivery of proteins enables efficient proteinbased genome editing in vitro and in vivo. Nat. Biotechnol. 33, 73-80. doi: $10.1038 /$ nbt.3081

Conflict of Interest Statement: The authors declare that the research was conducted in the absence of any commercial or financial relationships that could be construed as a potential conflict of interest.

Copyright (c) 2019 Ren, Landegger and Stankovic. This is an open-access article distributed under the terms of the Creative Commons Attribution License (CC BY). The use, distribution or reproduction in other forums is permitted, provided the original author(s) and the copyright owner(s) are credited and that the original publication in this journal is cited, in accordance with accepted academic practice. No use, distribution or reproduction is permitted which does not comply with these terms. 